\title{
Nordic
}

\section{StUdies IN EDUCATION}

Article | Peer-reviewed | Vol. 41, No. 3, 2021, pp. 185-200

\section{Synthesising Inclusive and Didactic Research - a Way to Ensure the Participation and Learning of Every Student?}

Catharina Tjernberg

Department of Educational Studies, Karlstad University, Sweden

Contact corresponding author: catharina.tjernberg@kau.se

Eva Heimdahl Mattson

Stockholm University and Department of Educational Studies, Karlstad University, Sweden

\begin{abstract}
The aim of this paper is to compare research criteria for inclusive education in relation to criteria for didactic research. The inclusive researchers that were selected defined inclusive education as removing barriers to social participation and learning for all students. The didactic researchers that we have selected referred to the tradition of successful reading and writing, focused on schools and teaching practices with favourable outcomes. The results indicated that the inclusive education researchers study school mainly from an organisational point of view. In contrast, the didactic researchers focus on a pedagogical approach, that is, on the teachers' teaching strategies concerning the ways in which each student learns best. Within both fields under study it is considered that in-service training is most effective when it is based on the teachers' actual working situation and when it emphasizes the importance of cooperative school cultures where the teachers also meet researchers. A reflection is that the inclusive education researchers in the study strive to transfer new knowledge to the teachers, in order to help them broaden their views on reducing social and organisational barriers to inclusion. The reading and writing researchers presented in this study represent a more dialectical process aimed at developing both the teachers' didactic professionalism, the researchers' own research questions and, in the end, the students' learning. Another reflection is that if inclusive education and didactic researchers were to develop collaborative research cultures, this would shorten the way to the common goal: to ensure the participation and learning of all students.
\end{abstract}

Keywords: inclusive education, reading and writing, study in excellence, participation, collaborative cultures, community of learners

Manuscript received: 20.05.2020. Manuscript accepted: 09.03.2021.

(C) 2021 C. Tjernberg \& E. Heimdahl Mattson. This is an Open Access article distributed under the terms of the Creative Commons CC-BY 4.0 License. ISSN 1891-5949, https://noredstudies.org

Citation: Tjernberg, C. \& Heimdahl Mattson, E. (2021). Synthesising inclusive and didactic research - a way to ensure the participation and learning of every student? Nordic Studies in Education, 41(3), 185-200. https://doi. org/10.23865/nse.v41.2831 


\section{Introduction}

In the debate on teachers' abilities to deal with increasing variation and diversity among school pupils, interest in both inclusive education research and didactic research has increased. Over the past few years a scientific base has been built up, but the expected effect of this increased knowledge has unfortunately not materialised. Many students experience difficulties in learning and an exclusionary situation at school. (Skolverket, 2017; Rose \& Shevlin, 2017; Fredriksson, 2012; Heimdahl Mattson \& Roll-Pettersson, 2007).

Both inclusive education and reading and writing research have produced knowledge of importance for schools, but they have developed in different fields. By "fields" we mean that research takes place in various contexts. In this article, we therefore present certain points which the approaches have in common, and we link together these fields of knowledge in order to develop teaching for the benefit of students' learning. Discussions in the two approaches have addressed similar issues but from different premises. Inclusive education research has focused on societal issues such as values, policy, power and organisation (Skrtic, Sailor \& Gee, 1996), and is seldom based on teachers' practical instruction (Florian, 2014). The field of reading and writing research, which we use in this paper as an example of an area of didactic knowledge, largely displays the same problem. Our growing theoretical knowledge of students' ways of learning reading and writing has to a great extent concerned various forms of learning processes, but here too it has only exceptionally been based on teachers' collective experiences. Thus, teachers have not identified research-based pedagogical knowledge as being sufficiently relevant and useful (Tjernberg \& Heimdahl Mattson, 2014). Integrating theory with practice seems to have been left to the teachers themselves with regard to both inclusive and reading and writing research. This agrees with Korthagen's (2007) conclusion that the gap between pedagogical research and teaching practice has in general widened. The democratic societies that are the focus of inclusive research are placing increasing demands on people's reading and writing competence. If students are to be able to absorb all the subjects, genres and various aims of reading, writing and expressing themselves in speech that they will meet in the future, they will need to develop strategies for this (Berge et al., 2019; Cummins, 2017; Gibbons, 2015; Pressley \& Allington, 2015; Tjernberg, 2013; Moats, 2009; Snow \& Juel, 2007; Crawford \& Torgesen, 2006;). They will also need to learn how to sort out and critically examine information in order to be able to argue and present their viewpoints so as to influence their own life situations and power relations in society in general. According to Cummins (2003) this means seeing education not merely as a learning process but also as a socio-political issue.

\section{Aims}

The aim of the present paper is to investigate and discuss criteria of research on inclusive education in relation to criteria of research on successful reading and writing instruction. By criteria we mean distinctive features and distinguishing factors in the literature we refer to. The issues we investigate are: 
- What similarities and differences exist between the criteria for inclusive education and those for successful reading and writing instruction?

- How can these similarities and differences be used to develop teaching practice for the participation and successful learning of all students?

\section{Theoretical perspectives}

The paper examines inclusive education and teaching and learning from an interactionistic (Bronfenbrenner \& Morris, 2007) and a socio-cultural perspective (Vygotskij, 1934/1962). Teaching, learning and participation are developed in a dialectical process between the individual and her or his environment.

Avramidis and Norwich (2002) analyse the difference between the terms integration and inclusion in the field of school and teaching. They describe integration as a kind of assimilation process in which the student's right to belong to the usual class is negotiable and dependent on her or his ability to fit into a school environment that is mainly unaffected. In contrast, the authors state, inclusion requires that the environment be changed so that each school accommodates each student and guarantees that she or he belongs to a community. Kotte (2017) also includes in the term "inclusion" the students' right to participate and contribute as well as the exchange of both social and knowledge learning.

According to the socio-cultural theory, the learning process is seen as something that the student participates in by means of pedagogical events, where concepts like zone of proximal development and mediating tools are essential (Vygotskij, 1934/1962). Proximal development may be described as the difference between what students can achieve on their own on the basis of their own ability, and what students can achieve with the support of teachers. According to this way of seeing teaching and learning, the tasks that the students are asked to perform should be a little tougher than they can manage on their own, based on their own ability, if there is to be any development (Gibbons, 2015). Gibbons calls this scaffolding and emphasizes the importance of both the students' and the teachers' active participation for successful learning.

The tools for communication may be written or material and they are used to create meaning. Language has a special position in the sociocultural tradition (Vygotskij, 1934/1962). The material tools consist of objects such as computers, telephones and cameras. According to Säljö (2014), it is hardly fruitful to distinguish between material and linguistic tools, since they occur together and presuppose each other.

\section{Method and implementation}

The references selected for this article are intended to provide a basis for reflection and discussion, they are not intended to give an overall picture of the research field. This study takes as its starting point the definition of the term inclusive eduction as the practices that reduce barriers for participation and learning for every student (Howes, Booth, Dyson \& Frankham, 2005, p. 146). We have thus omitted those studies that mix the terms inclusion and integration and use them synonymously. 
Regarding the field of inclusive education knowledge, we have referred to authors who define inclusive education as the practices that reduce barriers for participation and learning for every student and who consistently use the term inclusion in the meaning of accommodation. Hence, they do not mix the two terms inclusion and integration. Consequently, we have omitted those authors who confuse inclusive education with integration, since integration implies that the student's right to belong to the usual class is negotiated. The material was gathered by data collection, using the concepts above as a starting point.

Regarding the literacy field, we have chosen publications within the studies-inexcellence tradition since we were interested in studies that present teaching practices that promote opportunities for every student to participate and learn. This is in accordance with the aims and intentions of this study.

The didactic researchers in this paper refer to the tradition of successful reading and writing, focused on schools and teaching practices with favourable outcomes. Prominent researchers within this field are, for example, Pressley, Langer, Darling-Hammond and Cummins. These researchers concentrate on a pedagogical approach, that is, on the teachers' teaching strategies concerning the ways in which each student learns best.

To carry out this work we made use of qualitative analysis (Denscombe, 2009). One of the most basic tasks in a paper of this kind, according to Ryan and Bernhard (2003), is to recognize themes. One way of discovering themes, they claim, is to look for similarities, differences and repetitions in one and the same or in several texts. Looking for words, phrases and terms that occur frequently has also helped to identify themes.

An important concept in qualitative studies is transparency (Kvale, 2007; Spencer, Ritchie, Lewis \& Dillon, 2003). Part of the research process includes reporting on one's pre-understanding and experience in the chosen field. For us, this involves several years of teaching and research in the fields of education and special education, both in schools and in teacher education.

In order to increase the study's credibility and reliability, in this article we report on our own teaching and research experiences. We present examples of our own research within the various fields of knowledge and give previous publications as references (Heimdahl Mattson \& Roll-Pettersson, 2007; Tjernberg, 2013). In our opinion, in accordance with Kvale (2007), this makes the study more transparent since we embark on the research process with this knowledge and these experiences.

One of the authors has focused on research concerning inclusion and exclusion, based on several years teaching students with different disabilities in both segregated and more or less integrated school organisations. Conversations and interviews, primarily with students, but also with parents and teachers concerning their experiences and opinions of schooling, aroused our interest in inclusive education and its underlying theories. In consequence, this became a central part of this author's research and teacher education.

For about a decade, the other author has continuously visited and followed some excellent teachers and their students in the classroom, and engaged in reflective 
conversations with the teachers. The intention was to study how they designed and implemented their teaching with the participation and successful learning for every student in mind. We have also contributed to the study's transparency by describing the methods and how we selected certain studies and rejected others; we have also clarified what we mean by criteria.

We consider this account of our respective experiences, together with our desire to make the text communicable in both execution and revision, as decisive for the study's credibility and reliability.

\section{Results}

In the report on our results we present the criteria for each field separately in order to show their respective features. By "criteria" we mean distinctive features and distinguishing factors in the literature we refer to.

\section{Some criteria for inclusive education}

Skrtic, Sailor and Gee (1996), like other inclusive education researchers referred to here, are interested in school from an organisational and cultural perspective. According to the authors, so-called 'professional bureaucracies' are set up against 'adhocracies' or 'learning organizations' (p. 144).

Professional bureaucracies are based on various kinds of specialised knowledge in the school staff, knowledge that is intended to serve different categories of students and their preconceived needs. They share various resources but do their work on their own within their respective fields of knowledge.

In contrast, a learning organisation is described as a reflective and cooperating school culture where problems are solved by having discussions between equal members and where different professional knowledge and abilities are utilised. Thus, Skrtic et al. define inclusive education as a desire to replace traditional professional bureaucratic school culture with a learning organisation (p. 146). Skrtic (2005) sees what he calls 'personalising instruction' for all students as a central part of the development of such an activity. Ferguson (2008) also uses this term, which means that the pedagogical environment is accommodated to the student's unique circumstances. Nevertheless, neither of them goes into detail as to how to realize this aim in the classroom.

Concerning teachers' professional development towards inclusive education, Robinson and Carrington (2002) state that this must have the character of a continuous collegial cooperative culture, which aims at accommodating the teaching to suit all the students. The authors also consider that in-service training is most effective when it is based on the teachers' actual work.

Howes, Booth, Dyson and Frankham (2005) define inclusive practices as "... those, which tend to reduce barriers of learning and participation for all pupils" (p. 146). In a study of three different schools they found that such barriers were strikingly frequent. The project on which the study was based aimed at developing activities "... at a 
more general, cultural level than that which could be achieved by individual teachers in their classrooms ..." (p. 135). Thus, the focus was on environmental factors, those that originated in the school's social system and those that came from outside: curricula, agendas and regimes of accountability. The authors do not deny that the ways in which the teachers perceive the context, interpret the student's needs and formulate assignments in relation to the student are significant, but they emphasize that even though the teachers' individual development is of great importance, the aim of their project was to develop institutional change (p. 135).

Although the organisational context may influence the teachers' professional activities towards inclusion, it may also provide them with resources that have an exclusionary effect, claim Howes et al. (2005): "This is most evident when teachers have access to categorisation systems which allow them to label children and to build some understanding of how children should be taught on the basis of that label" (p. 140). In agreement with this, Avramidis and Norwich (2002) state in their survey of the literature on inclusive education that teachers from countries that offer the most sophisticated, segregated, educational provision were less supportive of inclusion. Also, according to these authors, several studies tend to reinforce the opinion "that special education qualifications acquired from pre- or in-service courses were associated with less resistance to inclusive practices" (p. 139). Support from the head teacher and from specialist resource teachers and more time to plan collaboratively are, according to Avramidis and Norwich, other important factors in shaping positive teacher attitudes to inclusion.

Heimdahl Mattson and Malmgren Hansen (2009) state that if the head teacher looks upon the special resource teacher as a supervising and coordinating person who helps provide solutions that do not exclude students from the ordinary school setting, and if educational and special educational solutions are created in a spirit of cooperation, this is in an inclusive direction.

Howes et al. (2005) also consider that a successful way to the understanding and development of inclusive practices is opened when a group of teachers is given an opportunity to discuss everyday professional challenges with a focus on barriers for participation and learning, not only with colleagues but also with outside researchers. As outsiders, the latter act as a resource for the teachers, helping to generate and analyse data to encourage their thinking about inclusion, and with this in view reduce social barriers. One conclusion of their study is that conversations and discussions of this kind have a lasting effect on the schools' development of attitudes and habits.

In an international survey of professional development for inclusive education, Wailtoler and Artiles (2013) discuss two studies (Deppeler, 2006; Layne et al., 2008), both of which show academic gains for all students as a result of university and teacher collaboration in research projects. It is worth noting that knowledge development was greatest for those students who had low levels of academic achievement prior to the research project. 
Wailtoler and Artiles (2013) describe three research categories in the field. One of these defines inclusive education as related only to ability differences and another focuses on gender and cultural differences. The third defines inclusive education as a process aimed at accommodating the teaching to all students. This idea is expressed in slightly different ways by different researchers. According to Ferguson (2008), the challenge is "to make inclusive education available to everybody, everywhere and all the time" (p. 109), whereas Florian (2014) defines inclusive education as "the shift in focus away from ideas of most and some learners to everybody" (p. 289).

Several researchers in inclusive education are critical of the emphasis on inclusion as a particular place (Nilholm \& Göransson, 2017; Florian, 2014; Ferguson, 2008). Skrtic et al. (1996) express it in the following way:

Contrary to what many people may think, the inclusive schools' movement represents school improvement on many levels for all students and not just physical placement of individuals with various disabilities in general classrooms. (p. 149)

According to Florian (2014) the inclusion process is contextual and can thus assume many forms depending on the classroom and school environments, different political systems and prevailing educational reforms. This raises important questions she claims: What can be considered "good practice" in inclusive education and how can evidence in such practice be judged? Concerning the second question, however, Florian states that it can be partly answered by means of studies of teachers' practices in which assumptions, principles and actions are carefully described:

We now know much more about the processes of inclusion and exclusion, but the task of generating new theoretical insights to guide development of practice remains. (p. 293)

\section{Some criteria for successful reading and writing instruction}

Our results here are based on studies that we have selected on the basis of the criteria for excellent teaching. This means that the focus of research is on successful teaching practitioners who create the conditions necessary for students' participation and learning.

Regardless of the teaching methods chosen, the teacher's theoretical knowledge and didactic skills are the decisive factor for the students' learning of reading and writing. (Neuman, 2017; Pressley \& Allington, 2015; Tjernberg \& Heimdahl Mattson, 2014; Cummins \& Persad, 2014; Tjernberg, 2013; Timperley, 2013; Wiliam, 2013; Cummins, 2012; Dillon, O'Brien, Sato \& Kelly, 2011; Kjällander, 2011; Moats, 2009; Hattie, 2009; Snow \& Juel, 2007; Langer, 2004). To give individual support and to motivate and inspire the students to take the next step into the zone of proximal development (Vygotskij, 1934/1962), the teacher must be able to identify where the students stand in their level of learning. 
Cummins (2017) develops the term "personalisation" as a didactic concept (cf. Skrtic, 2005; Ferguson, 2008). He emphasizes the importance of recognising the significance of human relations for all aspects of student learning. Strong relations between teacher and student can counteract the social disadvantages that many students find themselves in, and the interplay between teacher and student and between students, is of great importance.

Many of us have vivid memories of inspiring teachers who - just because they established a personal contact with us - got us to try harder in our school work than we did when the teacher only devoted himself to his subject teaching. (Cummins, 2017, p. 165)

In the opinion of Timperley (2013), teachers develop their professionalism partly by studying their own teaching in relation to the way the students develop their knowledge, and on this basis, develop adequate pedagogical activities - a continuous internal process. The students' confidence in their own ability grows through formative evaluations together with the teachers, whose positive expectations of the students' success corresponds to a continual effort to support their proximal development (Tjernberg \& Heimdahl Mattson, 2014). Normell (2002) states that teachers should follow the students to the places where knowledge is to be found, removing various barriers to learning that may occur on the way.

Matre and Fottland (2010) emphasize the importance of the students' being part of a community of learners for participation and learning. They stress the significance of every student seeing themselves as a part of this community of learners and really feel that they are participating. This feeling of participation, in the authors' opinion, is an expression of well implemented inclusive teaching, which in turn may be seen as the result of a conscious didactic design. This kind of conscious didactic design and implementation of the teaching requires understanding of both the method of working and the underlying theoretical ideas that form its basis and express it. (Tjernberg, 2013; Forsling, 2017).

The teacher's subject knowledge and knowledge of the processes that lie behind learning are coupled with experience-based and didactic skills. However, a skilful teacher is not competent merely in subject knowledge and many different strategies, methods and ways of working. According to Tjernberg (2013), she or he must also reflect continuously on her or his teaching and be ready to reconsider and adapt it in the light of how each individual student learns best.

Cummins (2003) develops this idea by claiming that if the students are to involve themselves seriously in the learning process, the teachers, in their interaction with the students, must recognise their cultural, linguistic and personal identities. Normell (2004) is on the same line when she states that knowledge develops as a result of mutual communication in which the surrounding expectations are important if the students are to develop their identities. 
Cummins (2017) gives examples of multilingual students, but the research he presents is relevant for all students' participation and learning. According to Cummins, the interaction between teacher and student is decisive for both cognitive engagement and identity development. When a student is given the opportunity to build on her or his previous knowledge, an engagement in learning is created, and there is no risk of getting stuck in thoughts about a lack of knowledge or a student's shortcomings. Cummins also emphasizes the importance of the students working together and learning together, and that the teacher and the students respect and are respected by each other. The result, he claims, is a positive spiral of learning and self-confidence among the students. Wiliam (2013) is on the same line, stressing the importance of the students' learning with and from each other. Among more recent research that deals with the ways the teaching of writing can be implemented in the classroom, we would like to mention the Norm project in Norway (Berge et al., 2019). This presents a way of teaching writing that is more systematic and with increased interplay, where researchers in cooperation with teachers have formulated and developed expectancy norms for writing competence. Both the students' development of writing competence and the teacher's assessment competence are in focus. There are also American studies in which the focus is on the way written language practices can be successfully designed and implemented in early writing teaching (see Neuman, 2017).

The development of teacher professionalism should be continuous and related to the teaching (Long, 2011). Dana (2010) also claims that teachers' learning, both in teacher education and during work, takes place best in school practice. This is in accordance with Tjernberg's 2013 study of a successful school, which indicates the importance of collegial cooperation involving mutual, continual pedagogical discussion between teachers, but also between teachers and researchers. The teachers in this successful school stress the importance of preventing excluding arrangements. A specialist resource teacher located in the classroom, a committed head teacher and collegial cooperation are important elements in this context. A characteristic trait in these successful teachers, apart from a sound knowledge of the subject, is the ability to build up a trusting relationship with each student and a positive belief that everybody can and wants to learn:

Not to give up but to show the student: '... for your sake, I know you can do better. I know it will be better if you do it this way. I believe you can - I'm sure you can!' (Tjernberg, 2013, p. 177)

This agrees with what students think makes a good teacher (Heimdahl Mattson \& Roll-Pettersson, 2007). According to students, a good teacher teaches in a variety of ways, believes in the students' abilities and develops a good classroom climate where everyone feels important. One of the students describes it like this:

... a teacher who wants to co-operate and try new and unconventional solutions. He does not ignore the problem, but is interested, positive, fair, and goal-oriented. A 'good teacher' does not give up on a student. (p. 247) 
Cummins claims a fundamental principle:

If you want students to emerge from schooling after 12 years as intelligent, imaginative, and linguistically talented, then treat them as intelligent, imaginative, and linguistically talented from the first day they arrive in school. (Cummins, pers. comm., Oct. 4th, 2017)

Thus a significant factor is the teachers' continuous involvement in the pedagogical process in which each and every student is challenged in her or his development zone (Gibbons, 2015; Pressley \& Allington, 2015; Wiliam, 2013). The teachers' good theoretical knowledge is coupled with practical experience and implemented in their teaching in the form of activated knowledge (Tjernberg, 2013). Hattie (2009) describes this as the teacher "reading" the classroom and being more receptive to the students' various circumstances and needs.

In a comprehensive study of American schools, Langer (2000) identifies other significant features of successful reading and writing teaching. These are that the work is process-oriented, meaning that the teacher follows the student's learning in everyday work and that the student gets continuous support in the development of reading and writing skills (Wiliam, 2019; Pressley, 2012, 2006; Crawford \& Torgesen, 2006; Darling-Hammond, 2000). Like Cummins and Persad (2014), Langer (2004) emphasizes the importance of the teacher making clear connections between different school subjects, and what is to be learnt to the students' previous knowledge and experience.

\section{Summary of results}

Inclusive researchers' interests usually concentrate on societal and organisational issues. Reading and writing researchers focus to a large extent on the individual level, that is, didactic issues and learning processes. However, if the didactic measures are to be implemented, it is necessary to have the right organisational circumstances. There needs to be, for example, a strong leadership that is well informed about the pedagogical work and can create good conditions for collegial learning and differentiated training according to the circumstances and needs of the activities. Development of the teachers' professional competence can be seen as an ongoing, interactive social process with an organisation where time and communication are important factors (Tjernberg, 2013).

The researchers on inclusive education referred to in this work see school primarily from an organisational and cultural perspective. The focus is on societal features such as power relations and the schools' social systems and aims mainly at institutional change.

To sum up, inclusive education is defined as the challenge to reduce barriers, everywhere and always, to ensure the participation and learning of all students. The students' right to belong to the ordinary class is not negotiable (Florian, 2014; Ferguson, 2008; Howes et al., 2005; Avramidis \& Norwich, 2002; Robinson \& Carrington, 2002; Skrtic et al., 1996). Skrtic et al. (1996) and Ferguson (2008) emphasize the importance 
of 'personalising instruction', that is, that the pedagogical environment is adapted to each student's circumstances.

In order to create positive attitudes towards inclusion, it is important that teachers are given support by the head teacher and the specialist resource teacher (Heimdahl Mattson \& Malmgren Hansen, 2009; Avramidis \& Norwich, 2002). Referring to professional development, several of the inclusive researchers also emphasize the importance of a cooperative collegial culture in which teachers, together with other teachers on equal terms, reflect on professional challenges with a focus on inclusive education (Robinson \& Carrington, 2002; Skrtic et al., 1996). Howes et al. (2005) are of the opinion that it is an advantage if outside researchers can take part in this process in order to help the teachers analyse their experiences and develop their thoughts on inclusive education.

Reading and writing researchers focus on pedagogical activities and make visible the importance of consciously organised and well-structured teaching. Their work aims at individuals, that is, how individual students learn best. The researchers emphasize the importance of teachers having both subject knowledge and knowledge of learning processes in order to be able to meet the varied and different needs that exist within a heterogeneous group of students (Tjernberg \& Heimdahl Mattson, 2014). The importance of understanding and evaluating their own activities in the classroom is also highlighted (Timperley, 2013; Wiliam, 2019; Hattie, 2009).

A positive belief in the students and trusting relationships are emphasized as fundamental factors for all learning (Cummins, 2017, 2003; Tjernberg, 2013; Crawford \& Torgesen, 2006), as well as the teachers' continual involvement in the pedagogical process, where each and every student is challenged in her or his development zone.

According to Hattie (2009), the teacher is involved, active and competent and steps in consciously and in a structured manner. Hattie emphasizes the importance of clear goals, clear feedback and high expectations. Thus, the teacher actively follows the students' knowledge development and can thereby successively remove barriers to learning.

Collaborative learning, whereby the students' various differences are utilised in the teaching and the students learn with and from each other, is highlighted as a success factor (Wiliam, 2019). Tjernberg and Heimdahl Mattson (2017) also emphasize the importance of a cooperative research culture in which teachers and researchers, in various constellations, reflect together with the aim of developing teaching and learning, and with a view to encourage the students' proximal learning.

\section{Reflections}

One dividing line between inclusive research and research on successful reading and writing teaching may be described as the weight given to the environment and the individual respectively.

Inclusive researchers see schools primarily from an organisational and cultural perspective. Their interest is usually focused on societal factors such as power 
relations at various levels: schools' social systems and curricula, attitudes and values. Their aim is institutional change with the overall goal of eliminating obstacles to all students' participation and learning (e.g. Kotte, 2017; Florian, 2014; Ferguson, 2008; Howes et al., 2005; Skrtic et al., 1996).

In contrast, research on successful reading and writing teaching, as with didactic research in general, is mainly connected with the learning of the individual (Pressley \& Allington, 2015; Wiliam, 2019; Gibbons, 2009; Pressley, 2006). Interest is in general focused on learning processes and subject knowledge. The aim is to develop, on the basis of the school curriculum, the ways in which pedagogical activities in the classroom are designed, to understand how each individual student learns best and to be able to meet all the different needs that a heterogeneous student group can contain. Here, the teachers' teaching strategies are related to the students' level of learning and identity creation, and one and all shall have the possibility to succeed in the learning process.

The inclusive researchers emphasize the right of all students to participate and learn. The focus of their research is on the measures that decision makers and societal organisers at various levels must take so that these rights can be met. In contrast, the reading and writing researchers are less inclined to discuss the external democratic conditions needed for inclusive work. Instead, the question of how this can be carried out in the classroom is in the foreground.

Avramidis and Norwich (2002) claim that the teachers' emphasis on subject-matter affiliation is less compatible with inclusion than a focus on individual student differences. Researchers of successful reading and writing also highlight the importance of focusing on student differences. However, they maintain the significance of teachers' subject knowledge for promoting the students' development of scholarly language, learning, identity creation and critical functioning - as necessary conditions for participation and continued learning (Berge et al., 2019; Cummins, 2017; Cummins \& Persad, 2014; Moats, 2009; Neuman, 2017; Snow \& Juel, 2007; Tjernberg, 2013).

Representatives of both inclusive education research (Robinson \& Carrington, 2002) and successful reading research (Dillon et al., 2011) consider that in-service training is most effective when it is based on the teachers' actual work. According to the inclusive education researchers, professional development is promoted by a collegial culture in which teachers cooperate within and between schools. Howes et al. (2005) show how researchers in a project of this kind help teachers to uncover and analyse empirical data about students' experience and progress to encourage their thinking about inclusion, that is, to reduce social barriers.

The reading and writing researchers that we report on also highlight the importance of collaboration between teachers and between teachers and researchers. However, we would like to add a couple of dimensions here. In Tjernberg's study (2013) this collaboration takes the form of a mutual dialogue in search of knowledge. The gains are numerous; the researchers dress the teachers' tacit knowledge in words and in return are given an opportunity to renew and deepen their research questions thanks to the 
teachers' experiences and practices. The researchers' scientific base and the teachers' teaching strategies are developed, thereby promoting the students' proximal knowledge development, representing a continuous progression in learning at three different levels - a triple learning process (Tjernberg \& Heimdahl Mattson, 2017).

Both researchers on inclusive education (e.g. Heimdahl Mattson \& Malmgren Hansen, 2009; Avramidis \& Norwich, 2002) and on studies in excellence in reading and writing (e.g. Tjernberg, 2013) emphasize the importance of specialist resource teachers in the classrooms, collaborative colleagues and committed head teachers. Howes et al. (2005) and Tjernberg (2013) also stress the importance of researchers to give teachers an opportunity to discuss everyday professional challenges with a focus on barriers to inclusion and to successful teaching respectively.

Another interesting finding is that successful teachers in Tjernberg's study never mention the term inclusion. Nevertheless, they act inclusively with heterogeneous groups where every student is supposed to contribute to the totality and where no exclusive arrangements are involved. This is in agreement with Howes et al. (2005) and Avramidis and Norwich (2002) when they claim that the organisation context is supposed to influence the teachers' professional activities towards inclusion - or exclusion.

The researchers on inclusive education reviewed define the term inclusion as a process in which school and teaching are accommodated to suit all students. Thus, the student's right to participate and learn within the community is unconditional and can never be questioned. In contrast, the term integration means that the student's right to this is conditional. According to Avramidis and Norwich (2002), integration is synonymous with assimilation since the students are expected to adapt to an already existing activity. If this does not happen, they will be assigned to some form of segregated educational provision.

Despite the inclusive researchers' clear standpoint in favour of all students' right to inclusive activities, terms like "including students" (Waitoller \& Artiles, 2013, pp. 325-326) and "include somebody" (Hedegaard Hansen, 2012, p. 93) pop up as paradoxes in some of the texts under review, leading to the terms integration and assimilation and the conception of students as objects. With inclusion, however, the focus is on school organisation and teaching, and the ability to adapt to the students' differences in such a way that every student is given the opportunity to achieve proximal learning, identity creation and participation in a community. Thus, it is the activity itself that has to function inclusively, and the students are subjects and participants in accommodating activities. Consequently, the term "included student" seems to be irrelevant in a context where the practices are defined as "... those which tend to reduce barriers of learning and participation for all pupils" (Howes et al., 2005, p.146) or "... the shift in focus away from ideas of most and some learners to everybody" (Florian, 2014, p. 289).

This confusion of the terms integration and inclusion, as we see it, is common in educational research, in the political debate, in public documents and consequently, out in the field in school organisations and classrooms - thereby creating a barrier to the development of inclusive organisations and inclusive, successful teaching. 
In our opinion, inclusive research and didactic research are two important fields of knowledge that, through synthesising, should be able to show the way to adequate political and organisational decisions for an inclusive school and its practical pedagogical realisation. That is to say reflecting and collaborative research cultures in which questions and answers to school-political and teaching problems develop in discussions between members of equal merit and in which different research results and scientific methods are used to attain the common goal: the right to participation and proximal learning for all students.

\section{REFERENCES}

Avramidis, E. \& Norwich, B. (2002). Teachers' attitudes towards integration/inclusion: A review of the literature. European Journal of Special Needs Education, 17(2), 129-147.

Berge, K. L., Skar, G., Matre, S., Solheim, R., Evensen, L. S., Otnes, H. \& Thygesen, R. (2019). Introducing teachers to new semiotic tools for writing instruction and writing assessment: Consequences for students' writing proficiency. Assessment in Education: Principles, Policy \& Practice, 26(1), 6-25. https://doi.org/10.1080/0969594X.2017.1330251

Crawford, E. C. \& Torgesen, J. K. (2006). Teaching all students to read: Practices from reading first schools with strong intervention outcomes. Florida Centre for Reading Research.

Creese, A. \& Blackledge, A. (2015). Translanguaging and identity in educational settings. Annual Review of Applied Linguistics, 35, 20-35.

Cummins, J. (2003). Second language teaching for academic success: A framework for school language policy development. I K. Nauclér, (Ed.), A second language perspective on learning. Sigma förlag.

Cummins, J. (2012). The interaction of cognitive and sociocultural factors in the development of reading comprehension among immigrant students. Reading and Writing, 25(8), 1973-1990. https://doi.org/10.1007/s11145-010-9290-7

Cummins, J. (2017). Multilingual students. Effective teaching in a challenging time. Natur \& Kultur. Cummins, J. \& Persad, R. (2014). Teaching through a multilingual lens: The evolution of EAL policy and practice in Canada. Education Matters, 2(1), 3-40.

Dana, N. F. (2010). Teacher quality, job-embedded professional development, and schooluniversity partnerships. Teacher Education and Practice, 23(3), 321-325.

Darling-Hammond, L. (2000). Teacher quality and student achievement: A review of state policy evidence. Centre for the Study of Teaching and Policy, University of Washington.

Denscombe, M. (2009). Forskningshandboken: För småskaliga forskningsprojekt inom samhällsvetenskaperna [Research handbook: For small-scale research projects in social sciences]. Studentlitteratur.

Dillon, D. R., O’Brien, D. G., Sato, M. \& Kelly, C. M. (2011). Professional development and teacher education for reading instruction. In M. L. Kamil, P. D. Pearson, E. B. Moje \& P. P. Afflerbach (Eds.), Handbook of reading research 4 (pp. 629-660). Routledge.

Ferguson, D. L. (2008). International trends in inclusive education: the continuing challenge to teach each one and everyone. European Journal of Special Needs Education, 23(2), 109-120.

Florian, L. (2014). What counts as evidence of inclusive education? European Journal of Special Needs Education, 29(3), 286-294. 
Forsling, K. (2019). Designs for learning: Focus on special needs designs for digitalised literacy education in a Swedish lower primary school. Designs for Learning, 11(1), 108-117. https://doi. org/10.16993/dfl.106

Fredriksson, U. (2012). Hur 15-åringars läsning förändrats mellan 2000 och 2009: Resultat från PISA-undersökningarna [How the reading ability of 15-year-olds changed between 2000 and 2009: Outcome from the PISA survey] In U. Carlsson \& J. Johannisson (Eds.), The readers' market, the market's readers: A research anthology (SOU, 2012i:10, s. 95-110). Fritzes.

Gibbons, P. (2015). Stärk språket stärk lärandet [Strengthen the language strengthen the learning]. Hallgren \& Fallgren.

Hattie, J. A. C. (2009). Visible learning: A synthesis of over 800 meta-analyses relating to achievement. Routledge.

Hedegaard Hansen, J. (2012) Limits to inclusion. International Journal of Inclusive Education, 16(1), 89-98. https://doi.org/10.1080/13603111003671632

Heimdahl Mattson, E. \& Roll-Petterson, L. (2007). Perspectives of mothers of children with dyslectic difficulties concerning their encounters with school: A Swedish example. European Journal of Special Needs Education, 22(4), 409-423.

Heimdahl Mattson, E. \& Malmgren Hansen, A. (2009). Inclusive and exclusive education: Principals' opinions and experiences. European Journal of Special Needs Education, 24(4), $464-474$.

Howes, A., Booth, T., Dyson, A. \& Frankham, J. (2005). Teacher learning and the development of inclusive practices and policies: Framing and context. Research Papers in Education, 2o(2), 133-148.

Korthagen, F. A. J. (2007). The gap between research and practice revisited. Educational Research and Evaluation, 13(3), 303-310.

Kotte, E. (2017). Inclusive education. Malmö studies in educational sciences, nr. 81. Doctoral dissertation. Malmö University.

Kvale, S. (2007). Doing interviews. Sage.

Langer, J. A. (2000). Beating the odds: Teaching middle and high school students to read and write well (CELA Rep. No. 12014). Centre on English Learning and Achievement, State University of New York.

Langer, J. A. (2004). Getting to excellent: How to create better schools. Teachers College Press.

Long, R. (2011). Professional development and education policy: Understanding the current disconnect. Reading Today, 29(3), 29.

Matre, S., \& Fottland, H. (2010). Text, talk and thinking together - using action research to improve third grade childrens' talking, reading and identity construction. Nordic Studies in Education, 31(4), 258-274.

Moats, L. C. (2009). Knowledge foundations for teaching reading and spelling. Reading and Writing: An Interdisciplinary Journal, 22(4), 379-399.

Neuman, S. B. (2017). The information book flood: Is additional exposure enough to support early literacy development? The Elementory School Journal, 118(1), 1-27.

Nilholm, C. \& Göransson, K. (2017). What is meant by inclusion? An analysis of European and North American journal articles with high impact, European Journal of Special Needs Education, 32(3), 437-451, https://doi.org/10.1080/08856257.2017.1295638

Normell, M. (2002). Pedagog i en förändrad tid: Om grupphandledning och relationer i skolan [Educator in a changing time: About group tutoring and relationships in school]. Studentlitteratur.

Normell, M. (2004). Pedagogens inre rum: Om betydelsen av känslomässig mognad [The educator's inner room: About the significance of emotional maturity]. Studentlitteratur. 
Pressley, M. (2006). What the future of reading research could be. Paper presented at the International Reading Association Reading Research Conference, Chicago, IL.

Pressley, M. \& Allington, R. (2015). Reading instruction that works: the case for balanced teaching. Guilford publication.

Robinson \& Carrington (2002). Professional development for inclusive schooling, International Journal of Educational Management, 16(5), 239-247.

Rose, R. \& Shevlin, M. (2017). A sense of belonging: Children's views of acceptance in "inclusive" mainstream schools. International Journal of Whole Schooling, Special Issue, 65-80.

Ryan, G. W. \& Bernard, H. R. (2003). Techniques to identify themes. Field Methods, 15(1), 85-109.

Skolverket [National Agency for Education]. (2017). PIRLS 2016: Reading competence of Swedish students in Grade 4 from an international perspective. (Skolverkets rapport, 464). Skolverket.

Skrtic, T. M. (2005) A political economy of learning disabilities. Learning Disability Quaterly, 28, 149-155.

Skrtic, T. M., Sailor, W. \& Gee, K. (1996). Voice, collaboration, and inclusion: Democratic themes in educational and social reform initiatives. Remedial and Special Education, 17(3), 142-157.

Snow, C. E. \& Juel, C. (2007). Teaching children to read: What do we know about how to do it? In M. J. Snowling \& C. Hulme (Eds.), The science of reading: A handbook (pp. 501-520). Blackwell. Spencer, L., Ritchie, J., Lewis, J. \& Dillon, L. (2003). Quality in qualitative evaluation: A framework for assessing research evidence. National Centre for Social Research.

Säljö, R. (2014). Lärande i praktiken: ett sociokulturellt perspektiv. [Learning in practice: a sociocultural perspective]. Prisma.

Timperley, H. (2013). Learning to practise: A paper for discussion. Ministry of Education.

Tjernberg, C. (2013). Framgångsfaktorer i läs- och skrivlärande: En praxisorienterad studie med utgångspunkt i skolpraktiken [Success factors in teaching reading and writing: A praxisoriented study based on school practices] (Doctoral dissertation). Stockholm, Sweden: Stockholm University.

Tjernberg, C. \& Heimdahl Mattson, E. (2014). Inclusion in practice: A matter of school culture. European Journal of Special Needs Education, 29(2), 247-256. https://doi.org/10,1080/ 08856257. 2014,891336

Tjernberg, C. \& Heimdahl Mattson, E. (2017). From methods and concepts to triple learning processes in school, teacher education, and research. Nordic Studies in Education, 39(1), 35-45. https://doi.org/10.18261/issn.1891-5949

Vygotskij, L. S. (1934/1962). Thought and language. MIT Press.

Waitoller, F. R. \& Artiles, A. J. (2013). A decade of professional development research for inclusive education: A critical review and notes for a research program. Review of Educational Research, 83(3), 319-356.

Wiliam, D. (2019). Att följa lärande: Formativ bedömning i praktiken [To follow learning: Formative assessment in practice]. Studentlitteratur. 